Original article

Paediatrics Today 2016;12(1):169-175

DOI $10.5457 / \mathrm{p} 2005-114.153$

\title{
CARDIAC EVALUATION OF CHILDREN WITH CONGENITAL ANOMALIES OF THE KIDNEYS AND URINARY TRACT
}

\author{
Nedima Atić, Hidajeta Begić, Jasminka Ibrahimović, Snežana Zulić, Emina Osmanović
}

Children's Hospital, Department of Paediatrics, University Clinical Hospital Tuzla, Bosnia and Herzegovina

\footnotetext{
Correspondence: bbs.enes@bih.net.ba

Tel.: + 38761881630

Fax.: + 38735303730
}

Received: July 4, 2016

Accepted: August 4, 2016

Key words: Congenital heart disease Congenital anomalies of the kidneys and urinary tract $\cdot$ Association.

\begin{abstract}
Objective - The purpose of this investigation was to determine the frequencies and types of associated congenital heart disease and other cardiac lesions in children with congenital anomalies of the kidneys and urinary tract (CAKUT). Participants and method - This was a prospective cardiac evaluation of children with diagnosed CAKUT, conducted between January 2013 and December 2015 at the Department of Pediatrics of the University Clinical Hospital, Tuzla. All cases were reviewed for age, gender, consanguinity, occurrence of congenital heart disease (CHD) and CAKUT in family history. Cardiac examination included: physical examination, noninvasive blood pressure measurement, a twelve lead electrocardiogram and echocardiogram. Results - Complete cardiac examination was performed in 144 children with congenital anomalies of the kidneys and urinary tract. Clinically insignificant morphological or hemodynamical changes were noted in $13 \%$ or $9.0 \%$ children. Congenital heart disease was found in 32 (22.2\%), hypertrophic cardiomyopathy in 2 and pulmonary hypertension in 1 of the 144 children. In 4 children congenital heart disease was part of other known genetic syndromes, and all of these cases had severe CHD. In twenty-six or $76.5 \%$ of the total of 32 patients it was already known, and in $6(23.5 \%)$ CHD was discovered during this research. Ventricular septal defect was the most common malformation ( $13 \%$ or $40.6 \%$ of patients). Vesicoureteral reflux was the most frequent CAKUT associated with CHD. Conclusions - The results of this study showed a significant association between CAKUT and CHD. Therefore we suggest performing cardiac assessment of all children with CAKUT.
\end{abstract}

\section{Introduction}

Congenital anomalies of different systems are associated in a wide spectrum of combinations. Congenital anomalies of the kidneys and urinary tract (CAKUT) comprise a broad spectrum of renal and urinary tract malformations that occur in altogether approximately 3-6 per 1000 live born fetuses and cause neonatal death in 1:2000 births $(1,2)$. These anomalies account for about 40\%-50\% children with chronic kidney diseases worldwide, and represent a leading cause of end stage renal failure in children (2). CAKUT may occur as isolated malformations or develop in association with additional congenital abnormalities outside the urinary tract, or be a part of the clinical pic- 
ture of chromosomal abnormality or genetic syndromes. CACUT has a wide spectrum of clinical presentations, from a completely asymptomatic state to a state incompatible with life. Congenital heart disease (CHD) defines a large set of structural and functional defects that arise during cardiac embryogenesis. The total birth prevalence of CHD in Europe is 8.1 per 1000 liveborns $(3,4)$, with significant differences (3.9-50 per 1000 liveborns) throughout the world and over time. According to an epidemiological study from 2003, the prevalence of CHD in the Tuzla Canton, Bosnia- Herzegovina, was 6.12 per 1000 liveborns (5). In developed countries it is the main cause of mortality in early childhood and is responsible for one fifth of the total child deaths (6).

Several CHD are known to occur in children with CAKUT in syndromic or non-syndromic patterns, and as a result this co-occurrence is the subject of research for a genetic link between CAKUT and CHD (7). Clinically this means the increasing risk of morbidity and mortality in these children, in addition to the increasing risk for surgical correction. Previous studies have reported 20\%-30\% CAKUT in children with CHD (8), most of these results were obtained by clinical examination of children with CHD. In recent literature there are only a few studies which have described the frequency in the occurrence of CHD in children with CA$\operatorname{KUT}(9,10,11)$. In our practice all children with hemodynamically significant CHD and those with suspect chromosomal abnormalities or genetic syndromes are subjected to screening for CAKUT. Also children with severe forms of CAKUT undergo complete a cardiac examination.

We hypothesized that in some children with CAKUT, who normally would not be required to undergo cardiac or genetic examination, CHD may remain unrecognized. The purpose of this investigation was to deter- mine the frequencies and types of associated CHD in children with CAKUT.

\section{Material and methods}

This was a prospective evaluation of cardiac examinations in children with CAKUT, conducted between January 2013 and December 2015 (over a period of 2 years) at the Department of Pediatrics of the University Clinical Hospital, Tuzla. Children with diagnosed CAKUT, who were admitted to the Department of Nephrology or Outpatients' department of Nephrology in that period underwent targeted cardiac examinations. The study included all cases of CAKUT, those with previously known CHD that was discovered due to cardiac symptoms or as part of genetic examination, as well as those for whom this investigation was the first cardiac examination.

All cases were reviewed for age, gender, consanguinity, and occurrence of CHD and CAKUT in their family history. Data on the occurrence of associated anomalies in other systems (non-cardiac and non-renal), chromosomal anomalies and genetic syndromes were extracted from the available medical documentation.

Cardiac examination included physical examination, noninvasive blood pressure measurement, a twelve lead electrocardiogram and echocardiogram. Data from the cardiac auscultation performed were described as normal, normal with innocent murmur, and abnormal (12). Arterial hypertension was considered when systolic blood pressure and/or diastolic blood pressure were $\geq 95$ percentile for gender, age and height (13). Interpretation of data obtained by electrocardiogram (EKG) was described as normal (which included physiological changes in children) or abnormal (14). The echocardiogram was performed with M-mode; 2Dmode, pulsed, continuous and color-Doppler 
provided US system (Vivit 3, Sinc Master $550 \mathrm{~b}$ ), using a $4.4-8 \mathrm{MHz}$ transducer. Examination was done by the transthoracic approach, with the patient in the supine and left decubitus position. Cardiac anatomy was routinely assessed by a sequential segmental analysis, that included subcostal, both apical, both parasternal and suprasternal views (15). The results of the echocardiography were described as normal, or with insignificant morphological or hemodynamic changes, and finally as CHD. All cases of CHD were coded in the International Classification of Diseases (ICD) version 10 (Q20-26) (16). Cases of patent ductus arteriosus and patent foramen ovale in premature infants as the only finding, as well as bicuspid aortic valve were not included as CHD.

\section{Statistical analysis}

Descriptive statistics were reported as percentages with a $95 \%$ confidence interval, when indicated in cases of categorical variables. Median and range were used for age, given the wide variability in our series.

\section{Results}

We identified 151 patients diagnosed with CAKUT during the study period. Seven, or
$4.6 \%$, of them refused to participate. Complete investigations were performed in 144 children with CAKUT, 94 males and 50 females. One patient had chromosomal abnormalities, trisomy X (47XXX), four had genetic syndromes, and 12 had other (non-cardiac and non-renal) anomalies. The general clinical details of 144 children with CAKUT included in investigation are shown in Table 1.

The most frequent CAKUT was vesicoureteral reflux (30 children) representing $20.8 \%$ of the total CAKUT. The next most frequent anomaly was hydronephrosis, present in 29 children or $20.1 \%$ of all cases. All types of CAKUT and their association with CHD are listed in Table 2.

Fifty-one or $35.4 \%$ patients had already undergone cardiac examinations when they were enrolled in the study, while for the other $93 \%$ or $64.6 \%$ this was the first cardiac examination. Cardiac auscultation was normal in 78, an innocent murmur was audible in 28 and a pathological murmur or pathological change of sounds was found in 38 children with CAKUT. Arterial hypertension was noted in 4 children. Electrocardiography was normal in 119; pathological ECG was found in 25 children, 23 of those with CHD, and 2 children with a structurally normal heart. Clinically insignificant morphological or

\section{Table 1 General details of 144 children with CAKUT included in the investigation}

\begin{tabular}{ll}
\hline Clinical details & \\
\hline Age (median and range) & $4.63(0.02-16.5)$ \\
Male to female ratio & $1.5: 1$ \\
Bilateral renal or urinary tract lesions (n; \%) & $26(18.0)$ \\
Chromosomal abnormalities (n; \%) & $1(0.7)$ \\
Genetic syndromes (n; \%) & $4(2.8)$ \\
Other (non-cardiac and non-renal) anomalies (n; \%) & $12(8.3)$ \\
Family history of renal anomalies (n; \%) & $8(5.5)$ \\
Consanguinity (n; \%) & - \\
Control cardiac examination (n; \%) & $51(35.4)$ \\
First cardiac examination (n; \%) & $93(64.6)$ \\
\hline
\end{tabular}

CAKUT $=$ Congenital anomalies of the kidneys and urinary tract. 
Table 2 Types of CAKUT and their association with CHD in children included in investigation

\begin{tabular}{lll}
\hline CAKUT & Patients (n; \%) & CHD (n; \%) \\
\hline Vesicoureteral reflux & $30(20.8)$ & $9(30.0)$ \\
Hydronephrosis & $29(20.1)$ & $7(24.1)$ \\
Ureteropelvic junction obstruction & $29(20.1)$ & $5(17.2)$ \\
Renal agenesia/hypoplasia & $18 / 6(12.5 / 4.1)$ & $5 / 0(27.7 / 0)$ \\
Hypospadia & $6(4.1)$ & $2(33.3)$ \\
Uretheral/ renal pelvis duplication & $5(3.5)$ & - \\
Multicystic dysplastic kidney & $5(3.5)$ & $1(20)$ \\
Ectopic kidney & $4(2.8)$ & $1(25)$ \\
Megaureter & $2(1.4)$ & - \\
Ren arcuatus & $2(1.4)$ & - \\
Bladder exstrophy & $1(0.7)$ & - \\
Posterior urethral valves & $1(0.7)$ & $2(33.3)$ \\
Associated CACUT & $6(4.1)$ & $32(22.2)$ \\
\hline Total & $144(100)$ & \\
\hline
\end{tabular}

$\mathrm{CAKUT}=$ Congenital anomalies of the kidneys and urinary tract; $\mathrm{CHD}=$ Congenital heart disease.

Table 3 Distribution of results of cardiac examination in children with different types of CAKUT

\begin{tabular}{|c|c|c|c|c|c|c|c|c|c|c|c|c|}
\hline \multirow{2}{*}{ CAKUT } & \multirow{2}{*}{$\begin{array}{l}\text { Patients } \\
\text { (n) }\end{array}$} & \multirow{2}{*}{ NCE } & \multirow{2}{*}{$\mathrm{CNC}$} & \multicolumn{8}{|c|}{$\mathrm{CHD}$} & \multirow{2}{*}{$\begin{array}{l}\mathrm{CMP} \\
\mathrm{PH}\end{array}$} \\
\hline & & & & VSD & ASD & PDA & PS & AS & $\mathrm{TF}$ & $\mathrm{CoA}$ & $\mathrm{CCHD}$ & \\
\hline VUR & 30 & 20 & 1 & 2 & 3 & - & - & 1 & 1 & 2 & - & - \\
\hline Hydronephrosis & 29 & 20 & 1 & 2 & 2 & - & - & 1 & 1 & - & 1 & $1 / 0$ \\
\hline $\begin{array}{l}\text { Ureteropelvic } \\
\text { junction obstruction }\end{array}$ & 29 & 21 & 3 & 3 & - & 1 & 1 & - & - & - & - & - \\
\hline Renal agenesis/ hypoplasia & $18 / 6$ & $12 / 6$ & $1 / 0$ & $1 / 0$ & - & $0 / 1$ & $1 / 0$ & 1 & 1 & - & - & - \\
\hline Hypospadia & 6 & 2 & 2 & 1 & - & - & - & - & 1 & - & - & - \\
\hline $\begin{array}{l}\text { Uretheral/renal } \\
\text { pelvis duplication }\end{array}$ & 5 & 4 & 1 & 1 & - & - & 1 & - & - & - & - & - \\
\hline $\begin{array}{l}\text { Multicystic } \\
\text { dysplastic kidney }\end{array}$ & 5 & 3 & 1 & 1 & - & - & - & - & - & - & - & $1 / 0$ \\
\hline Ectopic kidney & 4 & 4 & - & - & - & - & - & - & - & - & 1 & - \\
\hline Megaureter & 2 & 1 & - & - & - & - & - & - & - & - & - & $0 / 1$ \\
\hline Ren arcuatus & 2 & 1 & 1 & - & - & - & - & - & - & - & - & - \\
\hline Bladder exstrophy & 1 & - & - & - & - & - & - & - & - & - & - & - \\
\hline Posterior urethral valves & 1 & 1 & - & - & - & - & - & - & - & - & - & - \\
\hline Associated CACUT & 6 & 2 & 2 & 1 & - & - & - & - & - & - & 1 & - \\
\hline Total & 144 & 96 & 13 & 13 & 4 & 2 & 3 & 2 & 3 & 2 & 3 & $2 / 1$ \\
\hline
\end{tabular}

CAKUT $=$ Congenital anomalies of the kidney and urinary tract; $\mathrm{CHD}=$ Congenital heart disease; $\mathrm{VSD}=$ Ventriclar septal defect; $\mathrm{NCE}=$ Normal cardiac examination; $\mathrm{CNC}=\mathrm{Clinical}$ nonsignificant change; $\mathrm{ASD}=$ Atrial septal defect; $\mathrm{PDA}=\mathrm{Patent}$ ductus arteriosus; PS=Pulmonary stenosis; AS=Aortic stenosis; TF=Tetralogy Fallot; $\mathrm{COA}=$ Coarctation of the aorta; $\mathrm{CCHD}=\mathrm{Complex}$ congenital heart disease; $\mathrm{CMP}=$ Cardiomyopathy; $\mathrm{PH}=$ Pulmonary hypertension; VUR=Vesicoureteral reflux.

haemodynamic changes were noted in 13 children. Three had a bicuspid aortic valve, 4 had mitral valve prolapse without mitral regurgitation and 6 others had valve regurgita- 
tion (mitral, aortic) in morphologically and structurally intact valves. CHD was found in $32(22.2 \%)$, hypertrophic cardiomyopathy in 2 and pulmonary hypertension in 1 of the 144 children with CAKUT. In 4 children $\mathrm{CHD}$ was part of known genetic syndromes, and all of these cases were major CHDs. Cardiac surgery was indicated in 15 or $46.9 \%$ of all the 32 children with associated CHD. Twenty-six or $76.5 \%$ patients of the total 32 $\mathrm{CHDs}$ were already aware of their association, and in $6(23.5 \%)$ CHD was discovered during the current research. Ventricular septal defect was the most common malformation (in 13 or $40.6 \%$ ), followed by atrial septal defect secundum type ( 5 or $15.6 \%$ ). The most frequent association of CAKUT with CHD was found in children with vesicoureteral reflux. Table 3 shows the distribution of the results of cardiac examinations in children with different types of CAKUT.

\section{Discussion}

This is the first prospective, observational study in our region, aim at detecting and defining the spectrum of associations of CHD and other cardiac changes in children with CAKUT. According to numerous epidemiological reports, CAKUT has been found to occur at the rate of one child in every 600 births $(1,2,17)$. The term "CAKUT" covers malformations of the kidney (renal agenesis, hypoplasia, dysplasia, double kidneys), anomalies of the ureter (obstructive, as seen in proximal ureteral stenosis, or refluxive). Anomalies of the bladder and urethra are also assigned to this group $(18,19)$. CAKUTs are presented as a group of diseases with different degrees of severity and many of them require a multidisciplinary approach, accurate diagnosis and good treatment. The current study included 144 children (0.2-16.5 years) with CAKUT, living in the Tuzla Canton area which has a population of 92,047 children aged 1-14 years (20). Regarding this data, it may be considered that this study included more than half of all the cases of CAKUT. Apart from its size, the sample contains a wide spectrum of malformations grouped in CAKUT. The three most frequent malformations were: vesicoureteral reflux, hydronephrosis and ureteropelvic junctional obstruction, and they constitute more than $60 \%$ of the sample. Primary vesicoureteral reflux is the most common CAKUT in childhood, which is diagnosed mostly after an episode of urinary tract infection (21). Routine screening of patients with urinary infection can the explain the high proportion of vesicoureteral reflux. Another CAKUT, bladder exstrophy, which we noted in only one case, is a very rare anomaly, occurring with a 2:1 male-female ratio (22). Bilateral lesions were found presented in $22.2 \%$ cases. We observed a very small percentage of known chromosomopathies, genetic syndromes and associated non-renal and non-cardiac anomalies in our sample, in comparison with data in the literature $(10,23)$. This may be explained in the most part by the fact that some were lost because they were in critically ill infants, but also by the absence of systematic genetic search in our practice. Positive family history of CAKUT was fond in only $5.5 \%$ of all cases, while the frequency of renal abnormalities in close relatives reported in the literature is higher $(23,25)$.

The percentage of trivial cardiac lesions without clinical significance in our series accounted for $9.0 \%$ of patients, and is parallel with the general child population. Arterial hypertension, found in three children, was part of the clinical picture of chronic kidney disease, and in one case there was renovascular hypertension. We found a total of 32 (22.2\%) children with CHD, which is compatible with other similar studies in the relevant literature $(9,10)$. In our investigation, $\mathrm{CHD}$ was the leading associated congenital 
malformation. According to the results of some other authors, although they reported a similar percentage, $\mathrm{CHD}$ occurrence was in third place (26). About two thirds of the cases of CHD, 65.6\%, were found with the three most frequent CAKUTs (vesicoureteral reflux, hydronephrosis and ureteropelvic junctional obstruction). The most common cardiac malformation was ventricular septal defect, which is similar to other investigations $(9,11,27)$. These data and data on the structure and frequency of other CHDs, atrial septal defect, pattern ductus arteriosus, tetralogy Fallot are in line with epidemiological population based studies $(1,4,5)$. All syndromic cases and 5 children with other associated non-renal anomalies had CHD, which suggested a genetic cause of this connection. We hypothesized that some of them are still unrecognized. In their retrospective study, Miller et al. (26) observed a higher frequency of specific combinations, such as hydronephrosis with cardiac malrotation, right ventricle obstruction intra-atrial and intraventricular communication. Our data did not prove any significant connection between specific CAKUT and CHD. Among the children with associated CHD, nearly half had major heart defects which required cardiac surgery. The majority of CHD (26 of the total of 32) had been detected earlier, because they had had cardiac symptoms, or during routine genetic testing. Although a small number of associated CHD were detected during this targeted search, this was very important for their future follow-up.

During the investigation we observed numerous limitations, which led to the fact that the results we obtained are not completely representative. The relatively small CAKUT population, missing data on autopsies and perinatal mortality, the lack of a uniform register of congenital malformations, and incomplete results of genetic testing are some of them.

\section{Conclusions}

The general characteristics of our sample indicated that the need for clinical access for all congenital pathologies required improving most segments of children health care. This means that the basis of the diagnostic evaluation of all congenital abnormalities is multidisciplinary work which includes the accepted diagnostic algorithms, possibilities of genetic testing and official registration. Based on the results of CAKUT and CHD association, we suggest performing cardiological assessment of all children with CAKUT. For investigation of specific associations, we will need to continue this targeted search and registration.

Authors' contributions: Conception and design: NA and $\mathrm{HB}$; Acquisition, analysis and interpretation of data: HB, NA, JI, SZ and EO; Drafting the article: HB and EO; Revising the article critically for intellectual content: $\mathrm{HB}$ and NA; Approved final version of the manuscript: $\mathrm{HB}$ and NA.

Conflict of interest: The authors declare that they have no conflict of interest.

\section{References}

1. Loane M, Dolk H, Kelly A, Teljeur C, Greenlees R, Densem J; EUROCAT Working Group. Paper 4: EUROCAT statistical monitoring: identification and investigation of ten year trends of congenital anomalies in Europe. Birth Defects Res A Clin Mol Teratol. 2011;91(Suppl 1):S31-43.

2. Yosypiv IV. Congenital Anomalies of the Kidney and Urinary Tract: A Genetic Disorder? International Journal of Nephrology. 2012;2012:909083. [cited 2016 June 28]. Available from:http://www. ncbi.nlm.nih.gov/pmc/articles/PMC 3363415.

3. Hoffman JI, Kaplan S. The incidence of congenital heart disease. J Am Coll Cardiol. 2002;39(12):1890-900.

4. Dolk H, Loane M, Garne E; European Surveillance of Congenital Anomalies (EUROCAT) Working Group. Congenital heart defects in Europe: prevalence and perinatal mortality, 2000 to 2005. Circulation. 2011;123(8):841-9. 
5. Begić $H$, Tahirović $H$, Mesihović-Dinarević S, Ferković V, Atić N, Latifagić A. Epidemiological and clinical aspects of congenital heart disease in children in Tuzla Canton, Bosnia-Herzegovina. Eur J Pediatr. 2003;162(3):191-3.

6. Heron M. Deaths: leading causes for 2004. Natl Vital Stat Rep. 2007;56(5):1-95.

7. San Augustin JT, Klena N, Granath K, Panigraphy A, Stewart E, Devine W, et al. Genetic link between renal birth defects and congenital heart disease. Nature Communications. 2016 :11103

8. Rosa RC, Rosa RF, Zen PR, Paskulin GA. Congenital heart defects and extracardiac malformations. Rev Paul Pediatr. 2013;31(2):243-51.

9. Adhivisam B, Prahlad N, Vijayakumar M, Nammalwar BR, Muralinath S. Cardiovascular malformations associated with urinary tract anomalies. Indian J Nephrol. 2005;15:8-9.

10. Stoll C, Dott B, Alembik Y, Roth MP. Associated nonurinary congenital anomalies among infants with congenital anomalies of kidney and urinary tract (CAKUT). Eur J Med Genet. 2014;57(7):322-8.

11. Voisin M, Djernit A, Morin D, Grolleau R, Dumas R, Jean R. Congenital heart diseases and urinary malformations. Arch Mal Coeur Vaiss. 1988;81(5):703-7.

12. Ratti C, Grassi L, De Maria E, Bonetti L, Borghi A, Cappelli S. Cardiac auscultation in children. Recenti Prog Med. 2014;105(12):469-72.

13. National High Blood Pressure Education Program Working Group on High Blood Pressure in Children and Adolescents. The Fourth Report on the Diagnosis, Evaluation, and Treeatment of High Blood Pressure in Children and Adolescents. Pediatrics. 2004;114(Suppl 2):1-48.

14. Dickinson DF. The normal ECG in childhood and adolescence. Heart. 2005;91(12):1626-30.

15. Anderson RH, Shirali G. Sequential segmental analysis. Ann Pediatr Cardiol. 2009;2(1):24-35.

16. Tenth International Classification of Diseases (ICD-10) 2nd ed. Geneva: World Healt Organisation: 2003.
17. Cocchi G, Magnani C, Morini MS, Garani GP, Milan M, Calzolari E. Urinary tract abnormalities (UTA) and associated malformations: data of the Emilia-Romagna Registry. IMER Group. EmiliaRomagna Registry on Congenital Malformations. Eur J Epidemiol. 1996;12(5):493-7.

18. Weber S. Novel genetic aspects of congenital anomalies of kidney and urinary tract. Curr Opin Pediatr. 2012;24(2):212-8

19. Rodriguez MM. Congenital Anomalies of the Kidney and the Urinary Tract (CAKUT). Fetal Pediatr Pathol. 2014;33(5-6):293-320.

20. Anonymous. Federation of Bosnia and Herzegovina in figuras. Federal Office of Statistics. Sarajevo;2011:16-21.

21. Mattoo TK. Vesicoureteral reflux and reflux nephropathy. Adv Chronic Kidney Dis. 2011;18(5):348-54.

22. Hindryckx A, De Catte L. Prenatal diagnosis of congenital renal and urinary tract malformations. Facts, Views \& Vision in ObGyn. 2011;3(3):165174.

23. Renkema KY, Winyard PJ, Skovorodkin IN, Levtchenko E, Hindryckx A, Jeanpierre C, et al. EUCAKUT consortium. Novel perspectives for investigating congenital anomalies of the kidney and urinary tract (CAKUT). Nephrol Dial Transplant. 2011;26(12):3843-51.

24. Bulum B, Ozçakar ZB, Ustüner E, Düşünceli E, Kavaz A, Duman D, et al. High frequency of kidney and urinary tract anomalies in asymptomatic first-degree relatives of patients with CAKUT. Pediatr Nephrol. 2013;28(11):2143-7.

25. Winyard P, Chitty LS. Dysplastic kidneys. Semin Fetal Neonatal Med. 2008;13:142-51.

26. Miller A, Riehle-Colarusso T, Alverson CJ, Frías JL, Correa A. Congenital heart defects and major structural noncardiac anomalies, Atlanta, Georgia, 1968 to 2005. J Pediatr. 2011;159(1):70-78.

27. Greenwood RD, Rosenthal A, Nadas AS. Cardiovascular malformations associated with congenital anomalies of the urinary system. Observations in a series of 453 infants and children with urinary system malformations. Clin Pediatr (Phila). 1976;15(12):1101-4. 